\title{
Formularul 230
}

Prof. univ. dr. Lucian CERNUȘCA

Universitatea „Aurel Vlaicu” din Arad

\begin{abstract}
Natural persons that may wish to direct a part (2\% and/or 3.5\%) of their annual income tax for 2019 to support non-profit entities, cult units and offer private grants can do so by submitting form 230, until 25 May 2020 inclusively. Thus, through the Order of the president of the National Agency for Fiscal Administration 614/2020, taxpayers who are natural persons can fill out a single form 230 (the new one) in order to direct a part of their annual income tax for 2019, without having to send the two existing forms (form 230 for incomes for the months of January-March 2019 and the other form for incomes for the months of April-December 2019).
\end{abstract}

Key terms: form 230, non-profit entity, cult unit, private grants, annual income tax

Termeni-cheie: formularul 230, entitate nonprofit, unitate de cult, burse private, impozit pe venitul anual

Clasificare JEL: K34

To cite this article: Lucian Cernușca, Formularul 230, CECCAR Business Review, № 4/2020, pp. 56-63, DOI: http://dx.doi. org/10.37945/cbr.2020.04.07

În conformitate cu prevederile legale în vigoare, contribuabilii pot direcționa o sumă reprezentând până la 3,5\% din impozitul aferent veniturilor anului 2019 pentru susținerea entităților nonprofit care se înființează și funcționează în condițiile legii și a unităților de cult, precum și pentru acordarea de burse private. Pentru exercitarea acestei opțiuni, contribuabilii vor completa și transmite formularul 230 „Cerere privind destinația sumei reprezentând $2 \%$ sau 3,5\% din impozitul anual pe veniturile din salarii și din pensii/Cerere privind destinația sumei reprezentând până la 3,5\% din impozitul anual datorat".

În vederea sprijinirii și simplificării acestui proces, prin ordinul președintelui ANAF nr. 614/2020 a fost aprobat un nou formular 230, care înglobează informațiile relevante din cele două formulare 230 existente la data apariției actului normativ.

Entitățile pot beneficia de sumele respective doar dacă figurează în Registrul entităților/unităților de cult pentru care se acordă deduceri fiscale.

Formularul se completează și se depune atât de către persoanele fizice care au realizat venituri din salarii și asimilate salariilor și/sau venituri din pensii din țara noastră, cât și de către cele care au obținut venituri din salarii și/sau pensii din străinătate, impozabile în România, în anul 2019.

Au posibilitatea exercitării acestei opțiuni și contribuabilii persoane fizice care obțin venituri:

- din activități independente/activități agricole impuse pe bază de normă de venit;

- din drepturi de proprietate intelectuală, altele decât cele pentru care venitul net se determină în sistem real;

- din cedarea folosinței bunurilor pentru care venitul net se determină pe baza cotelor forfetare de cheltuieli sau a normelor de venit. 


\section{- Completarea formularului 230 pentru susținerea entităților nonprofit/unităților de cult}

În funcție de natura venitului, opțiunea contribuabililor privind direcționarea unei sume reprezentând până la 3,5\% din impozitul aferent veniturilor anului 2019 pentru susținerea entităților nonprofit/unităților de cult, precum și pentru acordarea de burse private se exercită prin completarea și depunerea la organul fiscal central competent a declarației unice privind impozitul pe venit și contribuțiile sociale datorate de persoanele fizice, pentru activitățile impuse în sistem real, sau a formularului 230, după caz.

\begin{tabular}{|c|c|}
\hline Natura veniturilor obținute & Tipul formularului completat și depus \\
\hline $\begin{array}{l}\text { - venituri din salarii și asimilate salariilor; } \\
\text { - venituri din pensii; } \\
\text { - venituri din activități independente realizate } \\
\text { în baza contractelor de activitate sportivă pentru } \\
\text { care impozitul se reține la sursă }\end{array}$ & 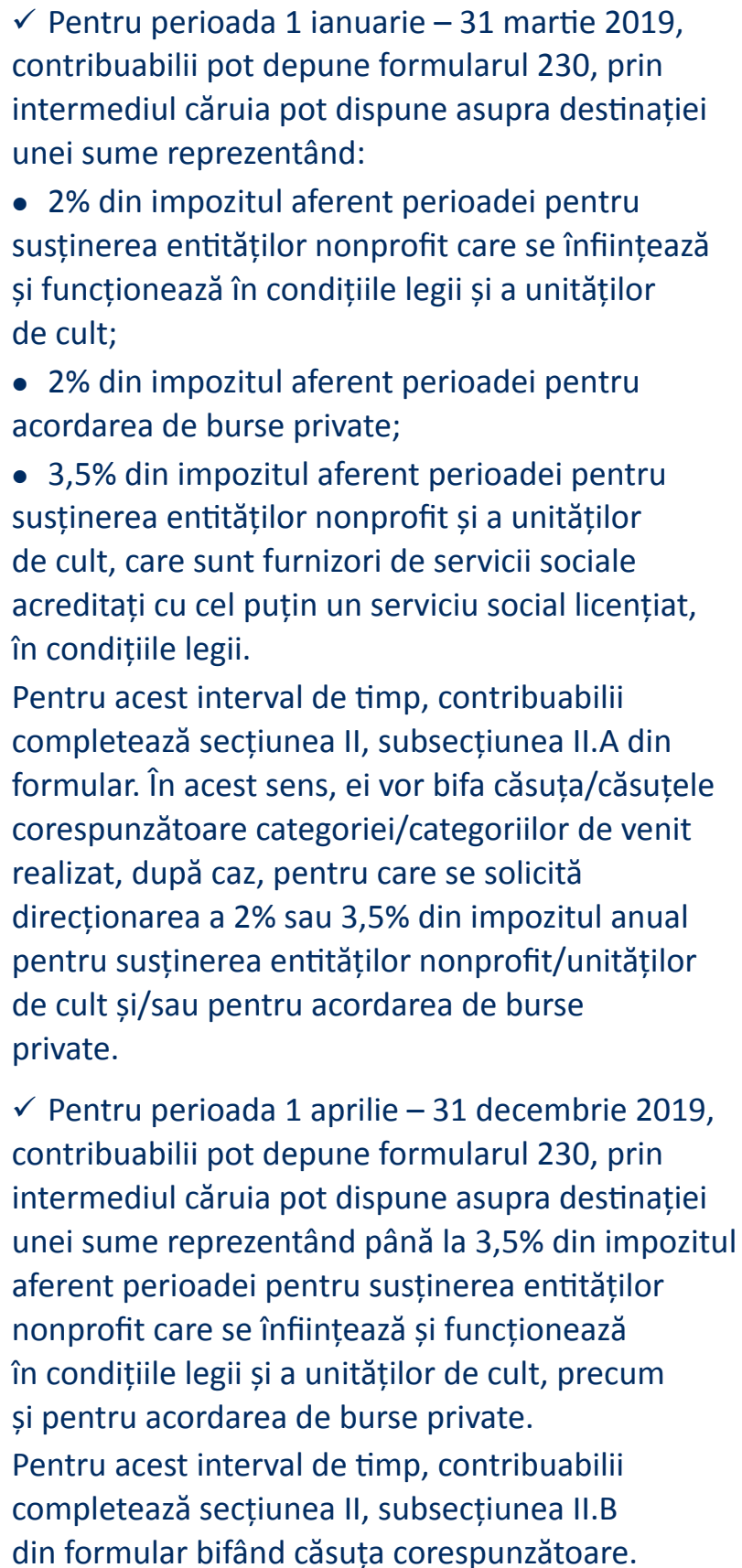 \\
\hline
\end{tabular}




\begin{tabular}{|l|}
\hline \multicolumn{1}{|c|}{ Natura veniturilor obținute } \\
\hline - venituri din activități independente/activități \\
agricole impuse pe bază de normă de venit; \\
- drepturi de proprietate intelectuală, altele decât \\
cele pentru care venitul net se determină în sistem \\
real;
\end{tabular}

- venituri din cedarea folosinței bunurilor pentru care venitul net se determină pe baza cotelor forfetare de cheltuieli sau a normelor de venit
- venituri din activități independente pentru care venitul net se stabilește în sistem real, pe baza datelor din contabilitate, care cuprind veniturile din activități de producție, comert, prestări de servicii, profesii liberale;

- venituri din valorificarea sub orice formă a drepturilor de proprietate intelectuală, pentru care venitul net se stabilește în sistem real, altele decât cele pentru care impozitul se reține la sursă; - venituri din cedarea folosinței bunurilor obținute din derularea unui număr mai mare de cinci contracte de închiriere sau subînchiriere la sfârșitul anului fiscal anterior celui de impunere și care, începând cu anul de impunere, sunt calificate în categoria veniturilor din activități independente; - venituri din închirierea în scop turistic a camerelor situate în locuințe proprietate personală, având o capacitate de cazare mai mare de cinci camere de închiriat, pentru care venitul net anual se determină în sistem real, pe baza datelor din contabilitate;

- venituri din activități agricole, silvicultură și piscicultură impuse în sistem real, pe baza datelor din contabilitate;

- câștigul net anual impozabil obținut din transferul titlurilor de valoare, din orice alte operațiuni cu instrumente financiare, inclusiv instrumente financiare derivate, precum și din transferul aurului financiar;

- venituri din alte surse;

- venituri din străinătate de aceeași natură cu cele obținute din România pentru care există dreptul de a dispune asupra destinației sumei reprezentând până la 3,5\% din impozitul pe venit datorat, prevăzute la art. $123^{1}$ alin. (1) din Codul fiscal.
Tipul formularului completat și depus

$\checkmark$ Pentru perioada 1 ianuarie - 31 decembrie 2019, contribuabilii pot depune formularul 230, prin intermediul căruia pot dispune asupra destinației unei sume reprezentând până la 3,5\% din impozitul aferent perioadei pentru susținerea entităților nonprofit care se înființează și funcționează în condițiile legii și a unităților de cult, precum și pentru acordarea de burse private.

Pentru acest interval de timp, contribuabilii completează secțiunea III din formular bifând căsuța corespunzătoare.

$\checkmark$ Pentru perioada 1 ianuarie -31 decembrie 2019, contribuabilii pot depune declarația unică, prin intermediul căreia pot dispune asupra destinației unei sume reprezentând până la 3,5\% din impozitul datorat pe venitul net/câștigul net anual impozabil determinat potrivit prevederilor art. 118 şi 119 din Codul fiscal pentru susținerea entităților nonprofit care se înființează şi funcționează în condițiile legii şi a unităților de cult, precum şi pentru acordarea de burse private, în conformitate cu reglementările art. $123^{1}$ din Codul fiscal. 
Formularul 230 se completează în două exemplare. Originalul se depune la organul fiscal competent, iar copia se păstrează de contribuabil sau de împuternicitul acestuia. Pentru persoanele fizice care au domiciliul fiscal în România, originalul se depune la organul fiscal în a cărui rază teritorială contribuabilul are adresa de domiciliu sau adresa unde locuiește efectiv, în cazul în care aceasta este diferită de cea de domiciliu. Pentru persoanele fizice fără domiciliu fiscal în România, originalul se depune la organul fiscal central competent.

Legislația în vigoare dă posibilitatea persoanelor fizice să opteze pentru direcționarea unei sume din impozitul anual pentru susținerea mai multor entități nonprofit/unități de cult, precum și pentru acordarea de burse private, completând în mod corespunzător formularul „Anexă nr... la Cerere privind destinația sumei reprezentând $2 \%$ sau 3,5\% din impozitul anual pe veniturile din salarii și din pensii/Cerere privind destinația sumei reprezentând până la 3,5\% din impozitul anual datorat". De asemenea, se completează corespunzător căsuțele prevăzute în formularul 230 cu numărul anexelor completate și depuse împreună cu acesta.

Cu caracter de noutate, contribuabilii au posibilitatea să își exercite opțiunea privind virarea unei părți din impozitul aferent veniturilor obținute în anul 2019 pentru aceiași beneficiari pentru o perioadă de cel mult doi ani, prin bifarea căsuței corespunzătoare din formular. În acest caz, în anul următor persoana fizică nu mai depune cererea, distribuirea efectuându-se de către organul fiscal competent pentru aceiași beneficiari, la nivelul plafonului admis de prevederile legale, fie în aceeași sumă dacă aceasta a fost completată în formular, fie în mod egal. Cererea poate fi reînnoită după expirarea perioadei de doi ani.

În situația în care formularul 230 se depune de către un împuternicit desemnat de contribuabil, se completează ultima rubrică, denumită „Date de identificare a împuternicitului”.

\section{- Completarea formularului 230 pentru acordarea de burse private}

Căsuța intitulată „Bursa privată” din cadrul formularului 230 se bifează de către contribuabilii care au efectuat cheltuieli cu burse private în cursul anului de raportare, în conformitate cu Legea nr. 376/2004 privind bursele private, cu modificările ulterioare, și solicită restituirea lor.

În această situație este necesară încheierea unui contract privind bursa privată, iar documentele privind plata sumelor respective trebuie anexate formularului depus la organul fiscal competent prin care se dispune destinația unei părți din impozitul aferent veniturilor anului 2019.

În formular se completează următoarele informații:

- numărul și data contractului privind acordarea bursei private;

- suma plătită de contribuabil în cursul anului de raportare pentru bursa privată;

- numărul și data documentelor care atestă plata bursei private.

\section{จ Modalitatea şi termenul de depunere a formularului 230}

Formularul 230 se poate depune, după caz:

- prin poștă, în mod individual sau pe bază de borderou;

- direct la registratura organului fiscal, în mod individual sau pe bază de borderou;

- prin mijloace electronice de transmitere la distanță.

Potrivit Ordonanței Guvernului nr. 6/2020 pentru modificarea și completarea Legii nr. 227/2015 privind Codul fiscal, precum și pentru reglementarea unor măsuri fiscal-bugetare, în acest an, termenul de 15 martie inclusiv prevăzut pentru depunerea formularului 230 se prelungește până la data de 25 mai 2020 inclusiv.

\section{○ Măsuri tranzitorii}

Din momentul apariției Ordinului președintelui ANAF nr. 614/2020, contribuabilii persoane fizice au posibilitatea de a completa un singur formular 230 (cel nou) în vederea direcționării unei părți din impozitul aferent tuturor veniturilor obținute în anul 2019, nemaifiind necesare cele două formulare existente la apariția acestui act normativ (formularul 230 aferent veniturilor obținute în perioada 1 ianuarie - 31 martie 2019 și cel aferent veniturilor obținute în perioada 1 aprilie - 31 decembrie 2019). 
Formularele 230 vechi deja înregistrate la organul fiscal competent până la data intrării în vigoare a noului ordin rămân valabile, ANAF operând aceste cereri și direcționând 2\% sau 3,5\% din impozitul aferent veniturilor obținute de contribuabili în anul 2019.

Tot ca măsură tranzitorie, contribuabilii care încă nu au depus formularele au posibilitatea în continuare, până la data de 25 mai 2020, să transmită la organul fiscal competent cele două formulare vechi 230 sau noul formular unic 230 .

\section{Exemplul 1}

O persoană fizică are un contract individual de muncă cu normă întreagă la o firmă din domeniul fabricării mobilei. Salariatul este angajat începând cu data de 01.01.2019 pe un post cu studii superioare și are o persoană în întreținere. Salariul de încadrare lunar este de 3.500 lei (nemodificat de la data angajării până în prezent). Persoana fizică deține funcția de bază la această societate și nu are alte contracte de muncă.

În data de 20.04.2020, angajatul depune formularul 230, prin intermediul căruia direcționează o parte din impozitul aferent veniturilor salariale pe anul 2019 pentru susținerea entității nonprofit X. X este înscrisă în Registrul entităților/unităților de cult pentru care se acordă deduceri fiscale și nu este furnizor de servicii sociale acreditat cu cel puțin un serviciu social licențiat.

\section{Ne propunem:}

a) să determinăm impozitul reținut prin stopaj la sursă pentru anul 2019;

b) să calculăm suma virată către entitatea nonprofit X și să prezentăm un extras din formularul 230.

a) Calculul salariului net și al impozitului reținut pe o lună:

\begin{tabular}{|c|c|c|}
\hline Angajat & Cota & Lei \\
\hline Salariu brut & & 3.500 \\
\hline CAS & $25 \%$ & 875 \\
\hline CASS & $10 \%$ & 350 \\
\hline Deducere personală & & 205 \\
\hline Venit bază de calcul pentru impozit & & 2.070 \\
\hline Impozit pe venit & $10 \%$ & 207 \\
\hline Salariu net & & 2.068 \\
\hline Angajator & Cota & Lei \\
\hline Contribuția asiguratorie pentru muncă & $2,25 \%$ & 79 \\
\hline Total contribuții angajat & & 1.432 \\
\hline Total contribuții angajator & & 79 \\
\hline Total taxe colectate la bugetul de stat & & 1.511 \\
\hline
\end{tabular}

Impozitul pe venit lunar este în sumă de 207 lei, iar cel anual, de 2.484 lei.

b) Contribuabilul dispune asupra destinației unei sume reprezentând $2 \%$ sau 3,5\% din impozit pentru susținerea entității nonprofit X, care nu este furnizor de servicii sociale acreditat cu cel puțin un serviciu social licențiat. X este înscrisă în Registrul entităților/unităților de cult pentru care se acordă deduceri fiscale.

Calculul sumei reprezentând 2\% sau 3,5\% din impozitul pe venit direcționat pentru susținerea entității nonprofit X: 


\begin{tabular}{|c|c|}
\hline Perioada & Suma virată entității nonprofit $X$ \\
\hline \multirow{3}{*}{ 01.01-31.03.2019 } & $\begin{array}{l}\checkmark \text { Persoana fizică dispune asupra destinației unei sume reprezentând } 2 \% \\
\text { din impozit pentru susținerea entității nonprofit X. }\end{array}$ \\
\hline & $\begin{array}{l}\text { Suma virată }=\text { Impozit pe venit pe perioada 01.01-31.03.2019 x 2\% = } \\
(207 \text { lei } \times 3 \text { luni) } \times 2 \%=12,42 \text { lei }\end{array}$ \\
\hline & $\checkmark$ Contribuabilul completează secțiunea II, subsecțiunea II.A.1 din formularul 230. \\
\hline \multirow{3}{*}{ 01.04-31.12.2019 } & $\begin{array}{l}\checkmark \text { Persoana fizică dispune asupra destinației unei sume reprezentând 3,5\% } \\
\text { din impozit pentru susținerea entității nonprofit X. }\end{array}$ \\
\hline & $\begin{array}{l}\text { Suma virată = Impozit pe venit pe perioada 01.04-31.12.2019 × 3,5\% = } \\
(207 \text { lei } \times 9 \text { luni) } \times 3,5 \%=65,2 \text { lei }\end{array}$ \\
\hline & $\checkmark$ Contribuabilul completează secțiunea II, subsecțiunea II.B din formularul 230. \\
\hline
\end{tabular}

Prezentăm mai jos un extras din formularul 230 completat de contribuabil:

II. Opțiunea privind destinația unei sume din impozitul datorat pe veniturile din salarii, pensii, precum și din activități independente realizate în baza contractelor de activitate sportivă pentru care impozitul se reține la sursă

II.A. Destinația sumei reprezentând 2\% sau 3,5\% din impozitul datorat pentru perioada 1 ianuarie - 31 martie 2019 inclusiv

II.A.1. Destinația sumei reprezentând $2 \%$ din impozitul datorat pentru susținerea entităților nonprofit care se înființează și funcționează în condițiile legii și a unităților de cult sau pentru acordarea de burse private, conform legii

II.A.2. Destinația sumei reprezentând 3,5\% din impozitul datorat pentru susținerea entităților nonprofit și a unităților de cult, care sunt furnizori de servicii sociale acreditați cu cel puțin un serviciu social licențiat, în condițiile legii

II.B. Destinația sumei reprezentând până la 3,5\% din impozitul datorat pentru perioada 1 aprilie - 31 decembrie 2019 pentru susținerea entităților nonprofit care se înființează și funcționează în condițiile legii și a unităților de cult, precum și pentru acordarea de burse private, conform legii

III. Opțiunea privind direcționarea unei sume reprezentând până la 3,5\% din impozitul anual datorat pentru perioada 1 ianuarie - 31 decembrie 2019 pentru susținerea entităților nonprofit care se înființează și funcționează în condițiile legii și a unităților de cult, precum și pentru acordarea de burse private, conform legii

\section{Susținerea unei entități nonprofit/unități de cult}

Opțiune privind distribuirea sumei pentru o perioadă de 1 an Opțiune privind distribuirea sumei pentru o perioadă de 2 ani Cod de identificare fiscală a entității nonprofit/unității de cult

Denumire entitate nonprofit/unitate de cult $\mathrm{X}$

\begin{tabular}{llll} 
& Cont bancar (IBAN) & ROXXX3OYYY Suma (lei) 78 \\
\cline { 3 - 3 }
\end{tabular} 


\section{Exemplul 2}

O persoană fizică, proprietar al unui spațiu pentru birouri, încheie la data de 22.12.2018 un contract de închiriere pentru acest imobil, valabil începând cu data de 01.01 .2019 , pentru o chirie de 2.000 lei/lună. Contribuabilul nu intră în categoria persoanelor exceptate de la plata CASS. Acesta direcționează un procent din impozitul pe venitul anual obținut din cedarea folosinței bunurilor pentru susținerea entității nonprofit Y, furnizor de servicii sociale acreditat cu cel puțin un serviciu social licențiat, înscrisă în Registrul entităților/unităților de cult pentru care se acordă deduceri fiscale.

Ne propunem:

a) să determinăm impozitul pe venitul net anual pe anul 2019;

b) să prezentăm modalitatea de direcționare a sumei reprezentând 3,5\% din impozit pentru susținerea entității nonprofit $Y$.

a) Proprietarul spațiului pentru birouri depune declarația unică la data de 28.01.2019 prin intermediul serviciului „Spațiul privat virtual” (SPV), în care își estimează un impozit anual în sumă de 1.440 lei:

\section{CAPITOLUL II. DATE PRIVIND IMPOZITUL PE VENITURILE ESTIMATE/NORMA DE VENIT A SE REALIZA ÎN} ROMÂNIA ȘI CONTRIBUȚIILE SOCIALE DATORATE ÎN ANUL 2019

\section{SECTIIUNEA II.1. DATE PRIVIND IMPOZITUL PE VENITURILE ESTIMATE DIN ROMÂNIA ÎN ANUL 2019}

\section{II.1.1.B. DATE PRIVIND IMPOZITUL ANUAL ESTIMAT}

1. Venit brut

2. Cheltuieli deductibile

3. Venit net anual estimat (rd. $1-$ rd. 2), din care:

3.1. Venit impozabil

4. Impozit anual estimat ( $\mathrm{rd} .3 .1 \times 10 \%)$

SECȚIUNEA II.3. SUMARUL OBLIGAȚIILOR PRIVIND IMPOZITUL PE VENITUL ESTIMAT ȘI CONTRIBUṬIILE SOCIALE ESTIMATE DATORATE PENTRU ANUL 2019

\section{II.3.1. Obligații privind impozitul pe venitul estimat}

1. Suma stabilită prin declarația curentă

2. Bonificația pentru plata integrală a impozitului, potrivit legii

0 lei

\section{DATE INFORMATIVE PRIVIND EFECTUAREA PLĂȚILOR}

II. Date informative privind stabilirea sumei de plată reprezentând impozit pe venitul estimat și contribuții sociale estimate datorate pentru anul 2019

\section{C.II.1. Obligații privind impozitul pe venitul estimat}

1. Suma stabilită prin declarația curentă

2. Bonificația pentru plata integrală a impozitului pe venit, potrivit legii

3. Suma de plată, potrivit legii (rd. $1-$ rd. 2)

b) Contribuabilul dispune asupra destinației unei sume reprezentând 3,5\% din impozitul pe venitul din cedarea folosinței spațiului pentru susținerea entității nonprofit Y. 
Suma virată = Impozit pe venitul din închiriere pe anul 2019 × 3,5\% = 1.440 lei x 3,5\% = 50,4 lei

Prezentăm mai jos un extras din formularul 230 completat de contribuabil:

III. Opțiunea privind direcționarea unei sume reprezentând până la 3,5\% din impozitul anual datorat pentru perioada 1 ianuarie - 31 decembrie 2019 pentru susținerea entităților nonprofit care se înființează și funcționează în condițiile legii și a unităților de cult, precum și pentru acordarea de burse private, conform legii

\section{Susținerea unei entități nonprofit/unități de cult}

Opțiune privind distribuirea sumei pentru o perioadă de 1 an Opțiune privind distribuirea sumei pentru o perioadă de 2 ani

Cod de identificare fiscală a entității nonprofit/unității de cult 2273888

Denumire entitate nonprofit/unitate de cult $\mathrm{Y}$

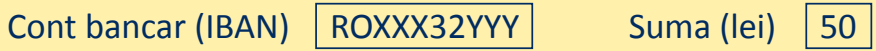

\section{Bibliografie}

1. Hotărârea Guvernului nr. $1 / 2016$ pentru aprobarea Normelor metodologice de aplicare a Legii $\mathrm{nr}$. 227/2015 privind Codul fiscal, publicată în Monitorul Oficial nr. 22/13.01.2016, cu modificările şi completările ulterioare.

2. Legea nr. 227/2015 privind Codul fiscal, publicată în Monitorul Oficial nr. 688/10.09.2015, cu modificările și completările ulterioare.

3. Ordinul președintelui Agenției Naționale de Administrare Fiscală nr. 50/2019 pentru aprobarea procedurii privind stabilirea de către organul fiscal central a sumei reprezentând $2 \%$ din impozitul anual datorat pentru susținerea entităților nonprofit care se înființează și funcționează în condițiiile legii și a unităților de cult sau pentru acordarea de burse private, conform legii, sau a sumei reprezentând 3,5\% din impozitul anual datorat pentru susținerea entităților nonprofit și a unităților de cult, care sunt furnizori de servicii sociale acreditați cu cel puțin un serviciu social licențiat, în condițiile legii, precum și a modelului și conținutului unor formulare, publicat în Monitorul Oficial nr. 40/15.01.2019.

4. Ordinul președintelui Agenției Naționale de Administrare Fiscală nr. 147/2020 pentru aprobarea Procedurii privind stabilirea sumei reprezentând până la 3,5\% din impozitul anual datorat pentru susținerea entităților nonprofit care se înființează şi funcționează în condițiile legii şi a unităților de cult, precum şi pentru acordarea de burse private, conform legii, precum şi a modelului şi conținutului unor formulare, publicat în Monitorul Oficial nr. 44/22.01.2020.

5. Ordinul președintelui Agenției Naționale de Administrare Fiscală nr. $614 / 2020$ privind modificarea Ordinului președintelui Agenției Naționale de Administrare Fiscală nr. 147/2020 pentru aprobarea Procedurii privind stabilirea sumei reprezentând până la 3,5\% din impozitul anual datorat pentru susținerea entităților nonprofit care se înființează și funcționează în condițiile legii și a unităților de cult, precum și pentru acordarea de burse private, conform legii, precum și a modelului și conținutului unor formulare, publicat în Monitorul Oficial nr. 181/05.03.2020.

6. Ordonanța Guvernului nr. 6/2020 pentru modificarea şi completarea Legii nr. 227/2015 privind Codul fiscal, precum şi pentru reglementarea unor măsuri fiscal-bugetare, publicată în Monitorul Oficial nr. 72/31.01.2020.

7. https://static.anaf.ro/static/10/Brasov/Brasov/D230_2019.pdf 